\title{
1 Nanoplastic occurrence in a soil amended with plastic debris
}

2 Aurélie Wahl ${ }^{1}$, Corentin Le Juge ${ }^{1}$, Mélanie Davranche ${ }^{1}$, Hind El Hadri ${ }^{2}$, Bruno Grassi²,

3 Stéphanie Reynaud ${ }^{2}$, Julien Gigault ${ }^{1 *}$

4

$5 \quad{ }^{1}$ CNRS/ Univ. Rennes, Geosciences Rennes, UMR 6118, F35000 Rennes, France.

ABSTRACT: While several studies have investigated the potential impact of nanoplastics, proof of their occurrence in our global environment has not yet been demonstrated. In the present work, by developing an innovative analytical strategy, the presence of nanoplastics in soil was identified for the first time. Our results demonstrate the presence of nanoplastics with a size ranging from 20 to $150 \mathrm{~nm}$ and covering three of the most common plastic families: polyethylene, polystyrene and polyvinyl chloride. Given the amount of organic matter in the soil matrix, the discrimination and identification of large nanoplastic aggregates are challenging. However, we provided an innovative methodology to circumvent the organic matter impact on nanoplastic detection by coupling size fractionation to molecular analysis of plastics. While photodegradation has been considered the principal formation pathway of nanoplastics in the environment, this study provides evidence, for the first time, that plastic degradation and nanoplastic production can, however, occur in the soil matrix. Moreover, by providing an innovative and simple extraction/analysis method, this study paves the way to further studies, notably regarding nanoplastic environmental fate and impacts. 
Key Words: Nanoplastics, soil, municipal wastes, Py-GCMS, AF4

\section{Introduction}

Despite a consensus that plastic debris will accumulate in the environment, its presence has drastically increased, reaching almost 360 million tons in 2018 (PlasticsEurope 2019). Plastic pollution is now considered one of the main environmental challenges and represents an emerging threat for all living species, especially due to the chemical species (additives and other adsorbed elements) that are associated with plastics (Velzeboer, Kwadijk, et Koelmans 2014; Alimi et al. 2018; Davranche et al. 2019; Shen et al. 2019). Leading governments have even classified plastic pollution as a critical problem comparable to climate change (Programme 2016).

In marine systems, despite knowledge gaps regarding the occurrence and fate of microplastics, the recent discovery of nanoplastics (Ter Halle et al. 2017) has opened the door to new considerations in terms of their properties and environmental fate and behavior. Nanoplastics are defined as plastic particles with sizes covering the colloidal range (1 $\mathrm{nm}$ to 1 $\mu \mathrm{m})$ and with a Brownian motion in aqueous system (Gigault et al. 2018). By contrast, compared to marine systems, terrestrial systems are largely ignored, as noted by Rillig (2012).

However, plastic-based materials such as plastic mulches and polytunnels are widely used to increase agricultural production efficiency or life duration (Steinmetz et al. 2016; Liu et al. 2018; Gao et al. 2019). Sewage sludge products also contribute to the incorporation of microplastics into soils (Habib, Locke, et Cannone 1998; Corradini et al. 2019). Both inputs, together with many others (Hurley et Nizzetto 2018), such as landfills (He et al. 2019), lead to the accumulation of plastics in soils, which could represent an even larger pollution pool than that in the oceans (Horton et al. 2017). Once plastic debris is present in soil, it mixes and 
reacts with soil organic matter $(\mathrm{OM})$ and minerals and may persist for up to a few hundred years (Bläsing et Amelung 2018). The prolonged residence time of plastics in soil could lead to the formation of micro- and nanodebris. The formation of such debris represents a severe challenge for environmental protection, especially for long-term farming based on plastics utilization (Steinmetz et al. 2016). Some recent studies have started investigating nanoplastic impacts on soil biota (Zhu et al. 2018; Awet et al. 2018), their interactions with contaminants (Velzeboer, Kwadijk, et Koelmans 2014; Davranche et al. 2019) and their transport through model soils (Hu et al. 2020; Pradel et al. 2020). However, to the best of our knowledge, evidence of nanoplastics in a natural soil environment has never been demonstrated. This lack is clearly due to the need for appropriate analytical methodologies for the identification of nanoplastics in the complex and heterogeneous soil matrix (Pinto da Costa et al. 2019). The size, shape, concentration (at the trace level) and carbon composition of nanoplastics make their identification and quantification highly challenging, especially due to the amount of natural $\mathrm{OM}$, which is also composed of carbon and covers the entire colloidal size range.

Due to their small size and high surface reactivity, nanoplastics could exert a direct and indirect effect on soil ecosystems, including groundwaters. They could indirectly influence the soil physicochemical properties, whereas direct effects were already reported on soil microorganisms and fauna communities (Zhu et al. 2018; Awet et al. 2018). Since soils and groundwaters are major human resources, evaluating the occurrence, fate and impact of nanoplastics in soils is crucial and is a main political and governmental priority, leading to legislation such as the European Commission directive on plastics on soil regulation.

Regarding the difficulties to extract and detect nanoplastics in a soil matrix, our objective is not to realize an exhaustive study of nanoplastic presence in various kind of soils, but to demonstrate that nanoplastics are present and can be produced directly in the soil matrix. The challenge was here to find a soil sufficiently contaminated by plastics and for 
enough years to allow the potential production of nanoplastics. For this purpose, we chosen to work on a soil contaminated by plastic debris through several municipal waste amendments performed around fifteen to thirty years ago. Nanoplastics were extracted using a water extraction procedure and subsequently identified by an innovative high-resolution analytical method combining size fractionation and molecular analysis.

\section{Methods}

\subsection{Soil sampling and geochemical analysis.}

The soil samples are agricultural soils collected in central France in February 2018. They correspond to the upper most horizon (0 to $10 \mathrm{~cm}$, organo-mineral (Ah) horizon) of a well-drained cambisol (VWR classification), enriched in pebbles and developed from alluvial deposits. The contaminated soil received two household wastes amendments mostly composed of plastics around thirty and fifteen years ago. The wastes were crushed and mixed with organic compost that was spread on the soil. The field was regularly tilled and used as a meadow for the last ten years. Plastic debris is thus clearly visible on and in the soil horizons from the surface to $40 \mathrm{~cm}$ depth. Plastic crushing has probably promoted the plastics degradation in the soil ( $\mathrm{Ng}$ et al. 2018). Regarding the contamination origin, treatment and dates, this soil is therefore the ideal target for studying the potential nanoplastic production in a soil matrix.

A soil control was sampled from a non-amended plot close to the contaminated plot. The same extraction protocol and characterization methods were used for the amended and control soil samples. Soil samples were dried in ambient air, sieved at $2 \mathrm{~mm}$ and stored in ambient air in the dark. To ensure no plastic pollution, both soils were similarly stored and treated. The geochemical composition of both soil samples is summarized in the Supplementary Materials,

Table S1. Geochemical analyses were performed at the "Service d'Analyse des Roches et des Minéraux" (SARM). The major element concentrations were determined by inductively 
coupled plasma-atomic emission spectrometry (ICP-AES, Thermo ICap 6500). Trace element concentrations were determined by ICP-mass spectrometry (Thermo Elemental X7). The samples were digested by alkaline fusion using lithium metaborate $\left(\mathrm{LiBO}_{2}\right)$ as a fusion flux.

\subsection{Nanoplastic water extraction experiments.}

To extract nanoparticles from the soil samples, soil-water extraction was performed. Ultrapure water was added to soil at a soil/water ratio of 1:4 (200 g/800 g) and stirred at $300 \mathrm{r}$ $\min ^{-1}$ for $72 \mathrm{~h}$ without any $\mathrm{pH}$ adjustment. Soil solutions were sampled over time. After $\mathrm{pH}$ and conductivity measurements, each sample was filtered to $0.8 \mu \mathrm{m}$ (Sartorius filters). Total organic carbon (TOC) was determined using a TOC analyzer (Shimadzu TOC-V CSH). The accuracy of the TOC measurements was estimated at $\pm 5 \%$ for all samples using a standard solution of potassium hydrogen phthalate. The extraction experiments were performed in duplicate.

\subsection{Nanoplastics identification and characterization.}

Water-extract filtrates were fractionated by asymmetric flow-field flow fractionation coupled to UV spectroscopy and static light scattering (AF4-UV-SLS, Wyatt Technology, Germany, and Agilent Technologies, France). The AF4 channel thickness was fixed by a 250$\mu \mathrm{m}$ Mylar film. The channel had a length of $26.5 \mathrm{~cm}$ and a width that narrowed from 2.1 to $0.6 \mathrm{~cm}$. The accumulation wall was defined by a $10-\mathrm{kDa}$ PES membrane purchased from Wyatt Technology. The method used was described by Gigault et al. (2017). The detailed parameters are presented in the Supplementary Materials. Three hundred microliters of each sample were injected into the AF4 instrument. The sizes (gyration radius, $R_{g}$ ) obtained from SLS were determined by the first-order Berry model using ASTRA-6 software. The AF4 
instrument was calibrated (Supplementary Materials, Fig. S1) using polystyrene spherical models (PSL, NIST traceable standard) to convert the elution time for a sphere with the equivalent hydrodynamic diameter $\left(\mathrm{d}_{\mathrm{zH}}\right)$. Both the AF4 extracts and $<0.8 \mu \mathrm{m}$ water extract fractions were analyzed by pyrolysis (PY-3030D - Frontier Lab, Japan) coupled to gas chromatography and mass spectrometry (Py-GCMS). For this experiment, $40 \mu \mathrm{L}$ of sample was introduced into an analysis cup and placed on a heating table at $40^{\circ} \mathrm{C}$ until complete evaporation of the solvent. This step was repeated one time to concentrate the samples before injection. The method followed for Py-GC/MS was described by Dehaut et al. (2016), and the corresponding settings are detailed in the Supplementary Material. A blank control was performed to ensure that none of the instruments or materials contaminated the samples.

\section{Results and Discussion}

\subsection{Extraction and aggregation of the nanoparticle fraction.}

During soil-water extraction, $\mathrm{pH}$, conductivity and TOC were monitored in the $<0.8 \mu \mathrm{m}$ fraction of the soil water-extracts (Fig. 1). For the contaminated soil (Fig. 1.I), in the first $6 \mathrm{~h}$, TOC increased from 24 to $30 \mathrm{mg} \mathrm{L}^{-1}$ and then decreased to reach a pseudo equilibrium from $24 \mathrm{~h}$ with an average concentration of $23.7 \pm 1.8 \mathrm{mg} \mathrm{L}^{-1}$. The $\mathrm{pH}$ remained stable $(7.35 \pm 0.2)$, while the conductivity continuously increased along the experiment, from 59.0 to $325.7 \mu \mathrm{S}$ $\mathrm{cm}^{-1}$. The TOC variations could be explained by an aggregation. Aggregates were formed with the running time experiments and were removed by the filtration at $0.8 \mu \mathrm{m}$, leading to the TOC decrease. This hypothesis is also supported by the conductivity increase, which could be responsible of the colloids material aggregation. By contrast, the TOC, $\mathrm{pH}$ and conductivity of the control soil all increased along the experiment (Figure 1.II) but with values much lower than for the contaminated soil. The control soil did not reach equilibrium during the experiment. Moreover, the control soil has lower concentrations of $\mathrm{CaO}$ and $\mathrm{CO}_{2}$ total than the contaminated soil (Table S1, Supplementary Materials). The contaminated soil 
is thus enriched in carbonates as compared to the control sample. Such carbonates are

148 dissolved during the water-extraction which buffer the $\mathrm{pH}$ and involve the conductivity

149 increase. This carbonates enrichment could be the result of agricultural practices such as

150 liming but also of the presence of weathered plastics debris. Hahladakis et al. (2018) showed

151 that plastics can have carbonate-based fillers representing until $50 \%$ of the total plastic

152 weight.
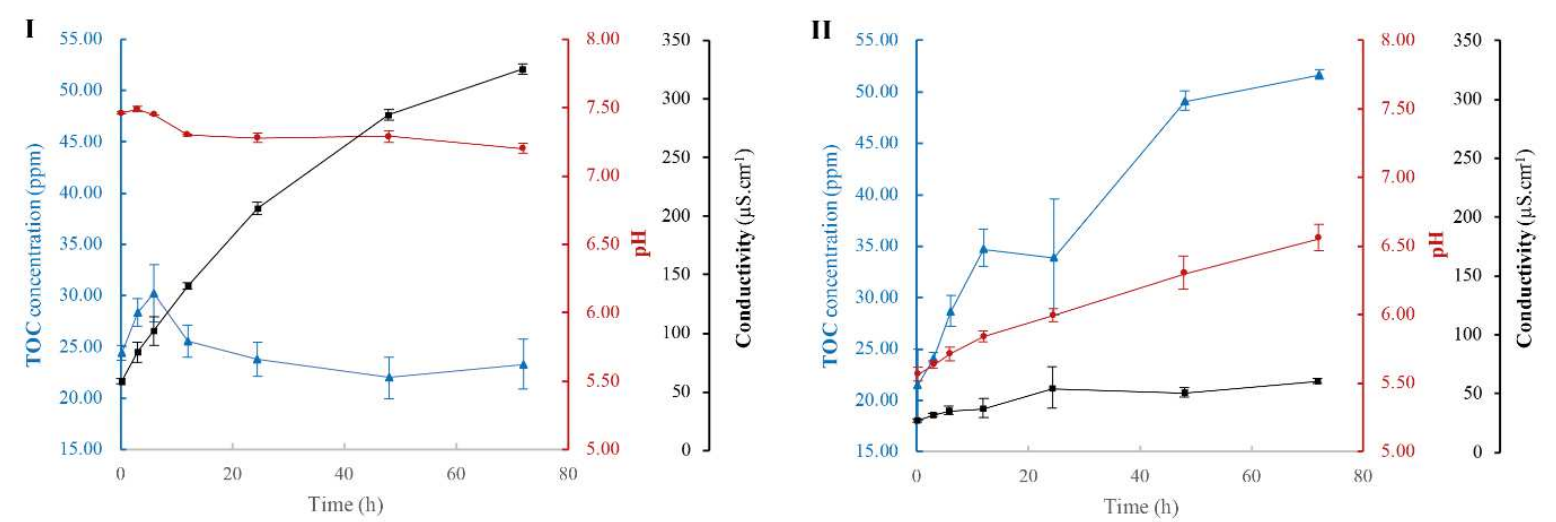

153

Fig. 1: Evolution of TOC, pH, and conductivity with extraction time. I: contaminated soil, II: soil control. The error bars correspond to the standard deviation calculated from duplicates.

To verify such hypothesis and better understand the behaviors in presence, the soil water extracts were characterized by AF4-UV-SLS. Regarding the TOC evolution, only 3 samples were collected and analyzed at 3 extraction times ( $6 \mathrm{~h}, 24 \mathrm{~h}$ and $72 \mathrm{~h})$. Fig. 2 presents the AF4-UV-SLS analysis results at different sampling times for the $<0.8 \mu \mathrm{m}$ solutions. According to the UV results, 3 populations (void time, A and B) were identified for all extraction times (Fig. 2.I). The void time population from 0 to $2.5 \mathrm{~min}$ corresponds to small particles (0 to $5 \mathrm{~nm}$ ) that are generally not colloidal (Chevalier et al. 2018) and correspond to low-molecular-weight OM. They were not considered in the present study. Two colloidal populations were identified: A from 7 to $12 \mathrm{~min}$ and $\mathbf{B}$ from 12 to $19 \mathrm{~min}$, which correspond to hydrodynamic sizes $\left(\mathrm{d}_{\mathrm{ZH}}\right)$ of 20 to $150 \mathrm{~nm}$ and $150 \mathrm{~nm}$ to $500 \mathrm{~nm}$, respectively (eq. (1), 
167 information on the particle size. From $6 \mathrm{~h}$ to $24 \mathrm{~h}$, while $\mathrm{R}_{\mathrm{g}}$ did not vary for $\mathbf{A}, \mathrm{R}_{\mathrm{g}}$ increased 168 from 200 to $600 \mathrm{~nm}$ for $\mathbf{B}$ and finally decreased at $72 \mathrm{~h}$ to reach $200 \mathrm{~nm}$, the initial value (Fig. 169 2.II). Such $R_{g}$ variations indicate particle aggregation (Frimmel, Kammer, et Flemming 2007). 170 To characterize the nature of the particle aggregation, $\mathrm{R}_{\mathrm{g}}$ was combined with the 171 hydrodynamic radius $\left(\mathrm{r}_{\mathrm{H}}-\right.$ obtained from AF4 elution time, eq. (1)) to determine the shape 172 factor $S$ (i.e., $\mathrm{R}_{\mathrm{g}} / \mathrm{r}_{\mathrm{H}}$ ). While $\boldsymbol{S}=0.778$ corresponds to hard spherical particles, a deviation to 1 173 indicates the presence of inhomogeneities on the sphere structure (Brewer et Striegel 2011). 174 Here, $S>>1$ indicates the formation of polymorphic aggregates. Our results therefore show 175 the formation of large and polymorphic aggregates. This aggregation process can be 176 confirmed by the UV signal evolution with time. From 6 to $72 \mathrm{~h}$, the UV signal of A 177 decreased, while it increased for $\mathbf{B}$, indicating the aggregation and transfer of the $\mathbf{A}$ 178 population to $\mathbf{B}$. Moreover, from 6 to $72 \mathrm{~h}$, the maximum of the peaks in the $\mathbf{B}$ population is 179 shifted to the right, which means that the particles size increased. In addition, from 6 to $72 \mathrm{~h}$, 180 the total UV signal decreased for the same elution time interval ( 7 to $20 \mathrm{~min}$ ). The total area 181 of the peaks was 367 at $6 \mathrm{~h}, 314$ at $24 \mathrm{~h}$ and 213 at $72 \mathrm{~h}$ which correspond to the TOC 182 decrease and particles loss. Thus, after $24 \mathrm{~h}$, large aggregates with sizes $>0.8 \mu \mathrm{m}$ were 183 formed, and the remaining particles in the $<0.8 \mu \mathrm{m}$ fraction were smaller, as confirmed by the 184 $\mathrm{R}_{\mathrm{g}}$ decrease. 

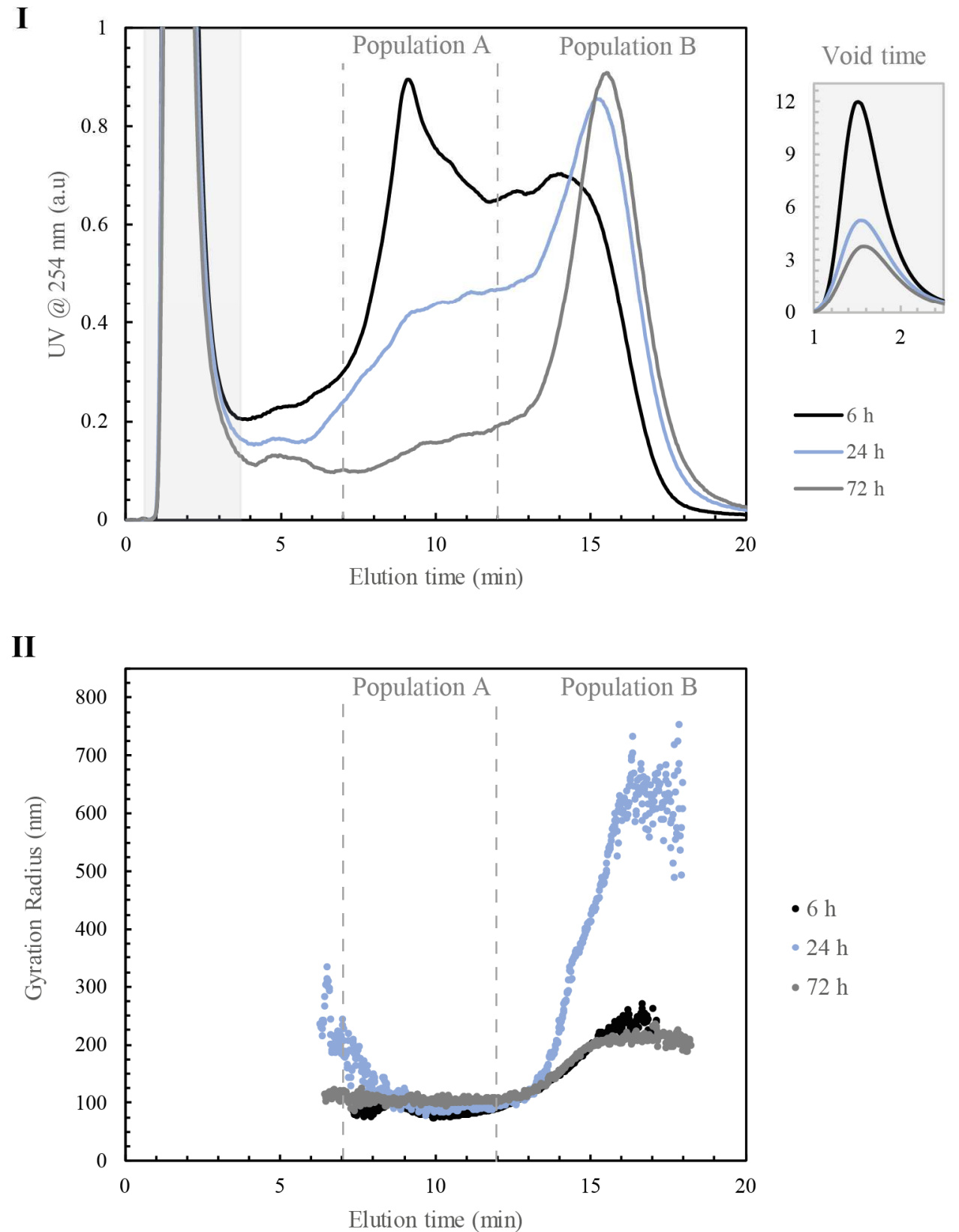

Fig. 2: I: Fractograms (UV trace at $254 \mathrm{~nm}$ ) of the soil water extracts at $6 \mathrm{~h}, 24 \mathrm{~h}$ and $72 \mathrm{~h}$ from the contaminated soil with respect to elution time. II: Evolution of the gyration radius $(\mathrm{Rg})$ with the elution time for the 3 soil water extracts.

\subsection{Are extracted nanoparticles nanoplastics?}

To discriminate the presence of anthropogenic nanoparticles, populations $\mathbf{A}$ and $\mathbf{B}$ identified by AF4 were collected and further analyzed by Py-GCMS. Analysis by Py-GCMS 
of different plastic materials provides specific molecular markers, which are reported in commercial databases (Tsuge, Ohtani, et Watanabe 2011; Supplementary Materials, table S2). Fig. 3 presents the pyrograms obtained at different extraction times for A only. The most abundant signal was obtained at $24 \mathrm{~h}$ (no signal at $72 \mathrm{~h}$ ). At $6 \mathrm{~h}$ and $24 \mathrm{~h}$, the global pyrograms present a series of multiple peaks at constant time intervals that are characteristic of polyethylene (PE) (Tsuge, Ohtani, et Watanabe 2011). By extracting the appropriate ion masses (m/z, Supplementary Materials, table S2), specific plastic molecular markers were identified at particular retention times $\left(t_{R}\right)$, as follows:

- Naphthalene (m/z 128) at $t_{R}=11.3$ min and naphthalene-1-methyl $(\mathrm{m} / \mathrm{z} 142)$ at $\mathrm{t}_{\mathrm{R}}=12.3$ min are characteristic of polyvinyl chloride (PVC; Fig. 3.II)

- Styrene monomer $(\mathrm{m} / \mathrm{z} 104)$ at $t_{R}=8.5 \mathrm{~min}$ and toluene $\left(t_{R}=7 \mathrm{~min}\right)$ are markers of polystyrene (PS; Fig. 3.III).

- Finally, as previously described, the pyrogram (Fig. 3.IV) shows the presence of PE with a series of alkenes: 1-decene (C10), 1-undecene (C11), 1-dodecene (C12), 1tridecene (C13), 1-tetradecene (C14) and 1-pentadecene (C15).

Moreover, as demonstrated by Ter Halle et al. (2017), the presence of the triplet nalkadiene, n-alkene and n-alkane with a bimodal distribution indicates a typical molecular formation pathway of PE during pyrolysis, rather than OM (Fig. 3.IV). Considering the PyGCMS results and by comparison with the control soil, nanoplastics are effectively present in the amended soil. Indeed, for the control soil, $24 \mathrm{~h}$ of extraction time also allowed the most important signals to be obtained, but these signals had typical markers that are characteristic of natural organic matter (Supplementary Materials, Fig. S2). No specific markers of plastics were determined in the control soil water extracts at any time.

For the contaminated soil, a first approximation gives a size ranging from 20 to 150 nm (A population) with heterogeneous shapes. Surprisingly, no signal was obtained for $\mathbf{B}$ 
despite the aggregation suggested by the AF4 results and TOC evolution. Different hypotheses could be made: (i) the nanoparticles identified in $\mathbf{A}$ aggregated to form micrometric particles that were transferred to $\mathbf{B}$ while the nanoplastics remained stable; or (ii) OM became predominant in $\mathbf{B}$ and interfered with the pyrolysis signal. Nanoplastics could be stabilized by their bindings with organic macromolecules or present a different aggregation behavior. However, the comparison of the water extracts with and without AF4 analysis and fraction collection (Fig. 4) showed that the pyrolysis signals were enhanced after size fractionation despite sample dilution. Therefore, AF4 can be used as a purification technique to remove organic and dissolved species that may interfere with detection. The amplification of the Py-GCMS signal of plastics after AF4 purification demonstrates that OM mitigates the detection of plastics. A higher proportion of OM than plastics could hide the plastic signature in the Py-GCMS results for the $\mathbf{B}$ population. This assumption explains the higher pyrolysis signal at $24 \mathrm{~h}$ than at $6 \mathrm{~h}$ and the plastic disappearance at $72 \mathrm{~h}$. To summarize, in the first $6 \mathrm{~h}$, OM was quickly released and aggregated after $24 \mathrm{~h}$. In both cases, OM was present in a higher proportion than plastics and interfered with the plastic pyrolysis signal until plastic detection became impossible at $72 \mathrm{~h}$. By contrast, at $24 \mathrm{~h}, \mathrm{OM}$ had just begun to aggregate, and its proportion was less than that of nanoplastics, enhancing the plastic PY-GCMS signal.

Finally, despite the increase in detection sensitivity achieved using A4F or other colloidal purification techniques (ultracentrifugation and ultrafiltration), it is still challenging to attribute specific markers to nanoplastics or OM. An interesting way to discriminate the OM contribution from that of plastics is the toluene-to-styrene ratio (Tol/Sty). Styrene and toluene are also produced during the pyrolysis of OM (Fabbri, Trombini, et Vassura 1998). Tol/Sty ranges from 4 to 5 for substrates of OM origin, in contrast to values of 0.001 to 1 for polystyrene plastics (Fabbri, Trombini, et Vassura 1998; Watteau et al. 2018). This difference 242 in ratios was confirmed by analyzing polystyrene nanoplastics and humic acid standards 
(Dignac et al. 2005). Tol/Sty did not exceed 0.03 for the polystyrene standards, while 6.3 was obtained for the humic acids. In the soil-water extracts, for A, Tol/Sty was 2.8. Recently, Watteau et al. (2018) compared the Tol/Sty values of leachates from a soil amended with municipal solid wastes. For the 0-2 $\mu \mathrm{m}$ fraction, potentially containing nanoplastics, Tol/Sty was approximately 3 to 5 for their nonamended soil sample (Watteau et al. 2018). Despite this difference in range from typical values, the authors claimed no plastic occurrence since Tol/Sty was over 1 . However, the confidence of the nanoplastics detection in our samples is based on (i) the coherent polystyrene detection associated with PE and PVC nanoplastics identification and (ii) the contribution of OM to plastics markers at the nanoscale (i.e., high specific surface area). Note that in the literature, Tol/Sty ratios were determined from microplastic debris with sizes generally $>500 \mu \mathrm{m}$. Nevertheless, plastic debris (micro- and millimetric) is generally coated by biofilms and OM with a thickness less than $0.4 \mu \mathrm{m}$ (Besseling et al. 2017). Therefore, the mass proportion of OM on large debris is insignificant. Nanoplastics (like other nanoparticles) are also associated with OM (surface sorption, heteroaggregate formation, surfactant-type associations, etc.) (Hotze, Phenrat, et Lowry 2010). However, regarding the high specific surface area and similar size of OM and nanoplastics, the OM mass contribution to core materials (i.e., plastics) is substantially larger (Delay et al. 2011). Indeed, by decreasing the size from $200 \mu \mathrm{m}$ to $200 \mathrm{~nm}$, the OM volume on plastic increases by more than 4000 times (Supplementary Materials, Fig. S3). This OM 262 distribution on nanoplastics leads to different Tol/Sty values from those of large 263 microplastics.

To summarize, in our experiment, nanoplastics are released into the soil solution concomitantly with OM, which controls the stability and aggregation pathways of nanoplastics (Hotze, Phenrat, et Lowry 2010). OM-nanoplastics associations are thus a key 267 factor in their detection in complex environmental matrices. This study demonstrated the 
268 mandatory use of AF4 or other size-separation techniques for proper detection. The 269 development of an analytical strategy based on Py-GCMS is therefore needed (pyrolysis 270 temperature optimization, ramp program, etc.). Preliminary sample treatment $\left(\mathrm{UV}\right.$ or $\left.\mathrm{H}_{2} \mathrm{O}_{2}\right)$ to 271 separate nanoplastics from OM is also of major concern in such analytical strategies. Finally, 272 this study also rises the question of plastics impacts on soil chemical properties. The 273 occurrence of plastic debris seems indeed to involve different geochemical behaviors of both 274 studied soils. 

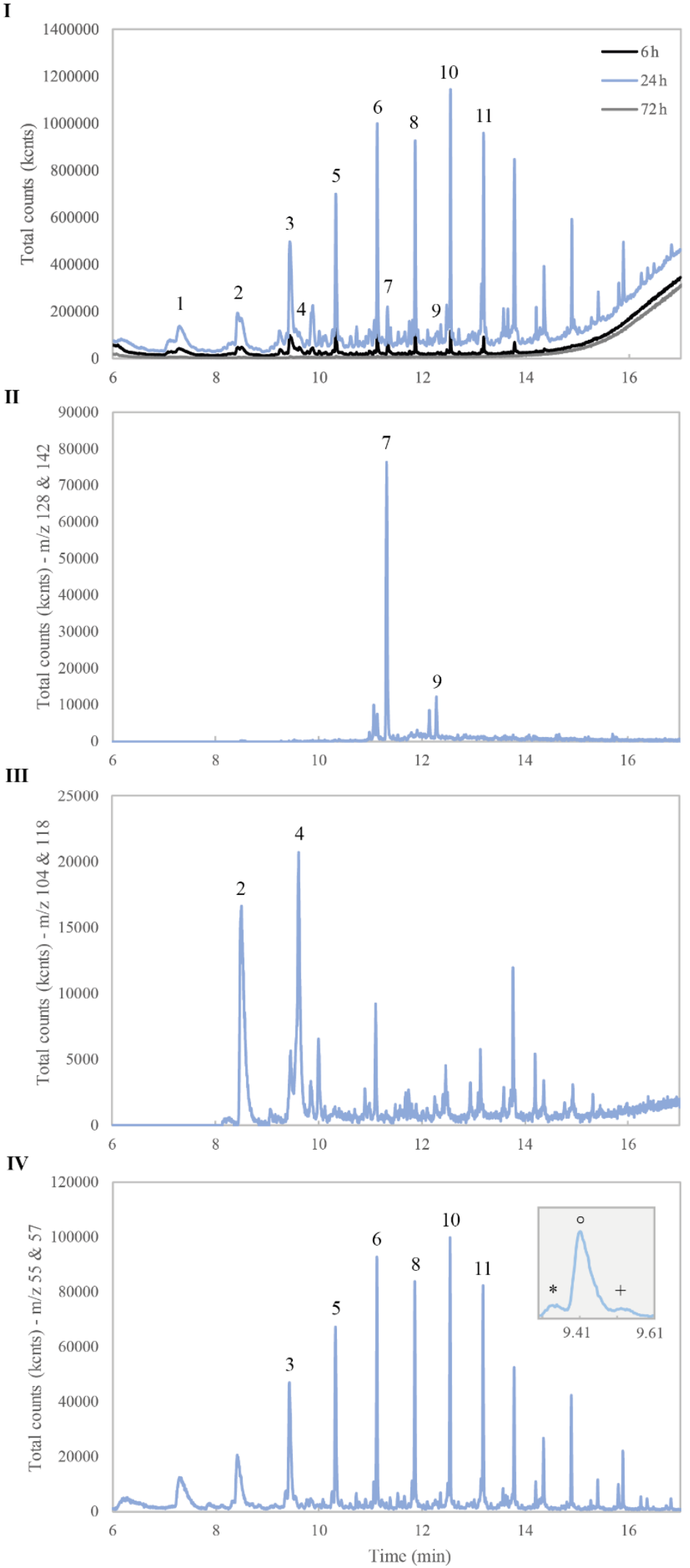

Fig. 3: I. Pyrograms of the 3 soil water extracts at 6,24 and $72 \mathrm{~h}$. Numbers correspond to specific markers of 277 plastic: 1: toluene, 2: styrene, 3: 1-decene, 4: a-methyl styrene, 5: 1-undecene, 6: 1-dodecene, 7: naphthalene, 8: 1-tridecene, 9: naphthalene 1-methyl, 10: 1-tetradecene, 11: 1-pentadecene. II, III and IV: Ion chromatograms at 

corner in IV details the triplet $\mathrm{n}$-alkadiene ${ }^{*}, \mathrm{n}$-alkene ${ }^{\circ}$ and $\mathrm{n}$-alkane ${ }^{+}$.
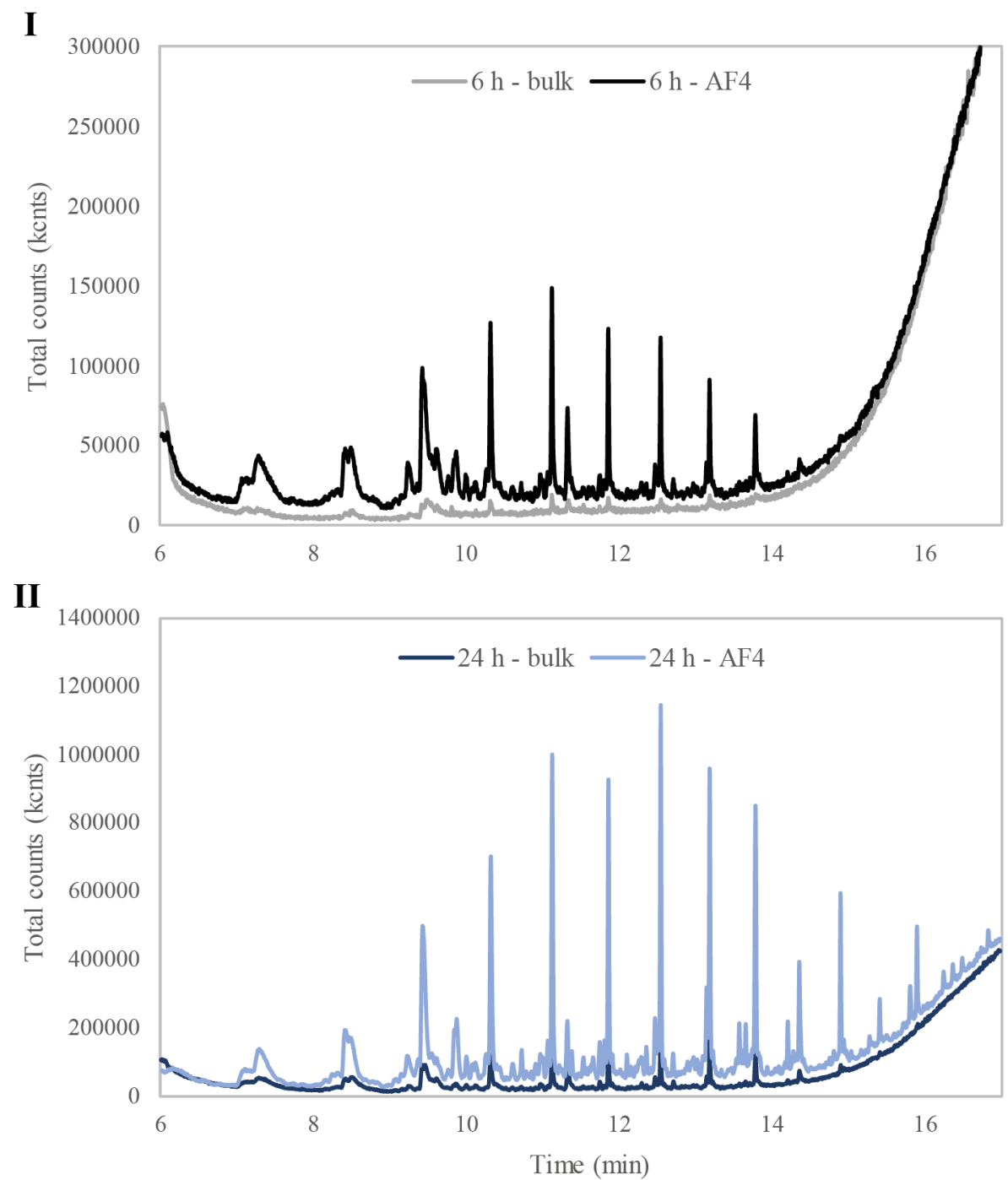

Fig. 4: Comparison between bulk solutions and solutions fractionated by AF4. I: 6 h, II: 24 h.

\subsection{Environmental implications.}

In addition to the first proof of nanoplastic presence in a soil contaminated by plastic debris, this study demonstrates that such debris is formed from larger pieces of plastic directly in the soil matrix. While the main degradation pathways of plastics in ocean and surface waters are mechanical abrasion and photo-thermo-oxidative degradation (Andrady 2015), these mechanisms only occur in the first centimeters of the soil. Unfortunately, experimental data on plastic degradation in soils are limited and rather scattered, as is knowledge of the 
parameters that control these degradation processes (Scalenghe 2018). To elucidate this uncertainty concerning nanoplastic formation pathways, the degradation of carrier plastic bags in soil, open-air and marine environments was recently compared over a 3-year period (Napper et Thompson 2019). After 3 years, plastic bags were still functional after exposure to soil and marine environments but had degraded into microplastics under open-air conditions. Therefore, degradation is slower in soil and marine environments than under open-air conditions. Our results suggest that in a 30-year time frame, plastic degradation in soil occurs to produce nanoplastics, which is similar to the degradation time observed in oceanic systems. This degradation pathway in soil thus suggests the implication of mechanisms other than photo-thermo-oxidative processes. Scalenghe (2018) reported that plastics degradation in soil could be enhanced by microorganisms.

Nanoplastics production in soil also raises the question of their environmental fate and their final impact on living organisms. The nanoscale of nanoplastics allows them to pass through the cell membranes (Bouwmeester, Hollman, et Peters 2015). As soils support our food sources, there is an urgent need to investigate the fate of nanoplastics: Are they taken up by plants? Do they accumulate in the food chain? Are they transferred to surface and groundwater? Their ability to cotransport contaminants (Velzeboer, Kwadijk, et Koelmans 2014; Davranche et al. 2019) as well as to release additives in the environment (Shen et al. 2019) could also impact water quality. These issues represent considerable societal and economic impacts that need to be urgently characterized to better anticipate them.

To conclude, it is important to note that the aim of the present study was not to provide an exhaustive study of the nanoplastic occurrence in various soil families and pedo-climatic conditions. Regarding that no study has already provided evidence of the potential nanoplastic production and presence in natural soil under environmental conditions, we chose to study a soil sample contaminated in plastics during a sufficient timeframe to be able to prove that 
nanoplastics can be produced directly in a soil matrix. For this, we developed an innovative and single extraction/analytical procedure allowing to detect nanoplastics even with a high amount of OM. Moreover, the present results suggest that nanoplastic production in soil seems to be rather slow, 30 years maximum, since photo-degradation is only limited to the first $\mathrm{cm}$ of the uppermost soil horizon.

\section{Supplementary Materials}

Table of the elementary composition of the top soil of the contaminated and the uncontaminated soil (Table S1), detailed methods, A4F calibration (Fig. S1), plastic markers for the Py-GCMS detection (Table S2), pyrograms of the soil water extracts from the uncontaminated soil (Fig. S2), comparison between OM volume and plastic debris surface (Fig. S3).

\section{Acknowledgments}

This work was supported by the ADEME (French National Agency of the Environment and the Control of Energy) IMPACT program through the CINAPE (2019-2022) project coordinated by Julien Gigault.

\section{References}

Alimi, Olubukola S., Jeffrey Farner Budarz, Laura M. Hernandez, et Nathalie Tufenkji. 2018. «Microplastics and Nanoplastics in Aquatic Environments: Aggregation, Deposition, and Enhanced Contaminant Transport ». Environmental Science \& Technology 52 (4): 1704-24. https://doi.org/10.1021/acs.est.7b05559.

Andrady, Anthony L. 2015. «Persistence of Plastic Litter in the Oceans ». Marine Anthropogenic Litter. Springer, Cham, 57-72. 
Awet, T. T., Y. Kohl, F. Meier, S. Straskraba, A.-L. Grün, T. Ruf, C. Jost, R. Drexel, E. Tunc, et C. Emmerling. 2018. « Effects of Polystyrene Nanoparticles on the Microbiota and Functional Diversity of Enzymes in Soil ». Environmental Sciences Europe 30 (1): 11. https://doi.org/10.1186/s12302-018-0140-6.

Besseling, Ellen, Joris T. K. Quik, Muzhi Sun, et Albert A. Koelmans. 2017. «Fate of nano- and microplastic in freshwater systems: A modeling study ». Environmental Pollution 220 (janvier): 540-48. https://doi.org/10.1016/j.envpol.2016.10.001.

Bläsing, Melanie, et Wulf Amelung. 2018. « Plastics in Soil: Analytical Methods and Possible Sources ». Science of The Total Environment 612 (janvier): 422-35. https://doi.org/10.1016/j.scitotenv.2017.08.086.

Bouwmeester, Hans, Peter C. H. Hollman, et Ruud J. B. Peters. 2015. « Potential Health Impact of Environmentally Released Micro- and Nanoplastics in the Human Food Production Chain: Experiences from Nanotoxicology ». Environmental Science \& Technology 49 (15): 8932-47. https://doi.org/10.1021/acs.est.5b01090.

Brewer, Amandaa K., et André M. Striegel. 2011. «Characterizing a Spheroidal Nanocage Drug Delivery Vesicle Using Multi-Detector Hydrodynamic Chromatography ». Analytical and Bioanalytical Chemistry 399 (4): 1507-14. https://doi.org/10.1007/s00216-010-4073-1.

Chevalier, Quentin, Hind El Hadri, Patrice Petitjean, Martine Bouhnik-Le Coz, Stéphanie Reynaud, Bruno Grassl, et Julien Gigault. 2018. « Nano-Litter from Cigarette Butts: Environmental Implications and Urgent Consideration ». Chemosphere 194 (mars): 125-30. https://doi.org/10.1016/j.chemosphere.2017.11.158.

Corradini, Fabio, Pablo Meza, Raúl Eguiluz, Francisco Casado, Esperanza Huerta-Lwanga, et Violette Geissen. 2019. «Evidence of Microplastic Accumulation in Agricultural Soils from Sewage Sludge Disposal ». Science of The Total Environment 671 (juin): 411-20. https://doi.org/10.1016/j.scitotenv.2019.03.368.

Davranche, Mélanie, Cloé Veclin, Anne-Catherine Pierson-Wickmann, Hind El Hadri, Bruno Grassl, Laura Rowenczyk, Aline Dia, et al. 2019. «Are Nanoplastics Able to Bind Significant 
Amount of Metals? The Lead Example ». Environmental Pollution 249 (juin): 940-48. https://doi.org/10.1016/j.envpol.2019.03.087.

367

Dehaut, Alexandre, Anne-Laure Cassone, Laura Frère, Ludovic Hermabessiere, Charlotte Himber, Emmanuel Rinnert, Gilles Rivière, et al. 2016. « Microplastics in Seafood: Benchmark Protocol for Their Extraction and Characterization ». Environmental Pollution 215 (août): 223-33. https://doi.org/10.1016/j.envpol.2016.05.018.

Dignac, M.-F., S. Houot, C. Francou, et S. Derenne. 2005. « Pyrolytic Study of Compost and Waste Organic Matter ». Organic Geochemistry 36 (7): 1054-71. https://doi.org/10.1016/j.orggeochem.2005.02.007.

«EUR-Lex - 32011L0065 - EN - EUR-Lex ». s. d. Consulté le 27 janvier 2020. https://eurlex.europa.eu/eli/dir/2011/65/oj.

Fabbri, Daniele, Claudio Trombini, et Ivano Vassura. 1998. « Analysis of Polystyrene in Polluted Sediments by Pyrolysis_-Gas Chromatography-Mass Spectrometry ». Journal of chromatographic science 36 (12): 600-604.

Frimmel, Fritz H., Frank von der Kammer, et Hans-Curt Flemming. 2007. Colloidal Transport in Porous Media. Springer Science \& Business Media.

Gao, Haihe, Changrong Yan, Qin Liu, Weili Ding, Baoqing Chen, et Zhen Li. 2019. « Effects of Plastic Mulching and Plastic Residue on Agricultural Production: A Meta-Analysis ». Science of The Total Environment 651 (février): 484-92. https://doi.org/10.1016/j.scitotenv.2018.09.105.

Gigault, Julien, Hind El Hadri, Stéphanie Reynaud, Elise Deniau, et Bruno Grassl. 2017. «Asymmetrical Flow Field Flow Fractionation Methods to Characterize Submicron Particles: Application to Carbon-Based Aggregates and Nanoplastics ». Analytical and Bioanalytical Chemistry 409 (29): 6761-69. https://doi.org/10.1007/s00216-017-0629-7.

Gigault, Julien, Alexandra ter Halle, Magalie Baudrimont, Pierre-Yves Pascal, Fabienne Gauffre, Thuy-Linh Phi, Hind El Hadri, Bruno Grassl, et Stéphanie Reynaud. 2018. « Current Opinion: What Is a Nanoplastic? » Environmental Pollution 235 (avril): 1030-34. https://doi.org/10.1016/j.envpol.2018.01.024. 
Habib, Daniel, David C. Locke, et Leonard J. Cannone. 1998. «Synthetic Fibers as Indicators of Municipal Sewage Sludge, Sludge Products, and Sewage Treatment Plant Effluents ». Water, Air, and Soil Pollution 103 (1): 1-8. https://doi.org/10.1023/A:1004908110793.

Hahladakis, John N., Costas A. Velis, Roland Weber, Eleni Iacovidou, et Phil Purnell. 2018. « An Overview of Chemical Additives Present in Plastics: Migration, Release, Fate and Environmental Impact during Their Use, Disposal and Recycling ». Journal of Hazardous Materials 344 (février): 179-99. https://doi.org/10.1016/j.jhazmat.2017.10.014.

He, Pinjing, Liyao Chen, Liming Shao, Hua Zhang, et Fan Lü. 2019. « Municipal Solid Waste (MSW) Landfill: A Source of Microplastics? -Evidence of Microplastics in Landfill Leachate ». Water Research 159 (août): 38-45. https://doi.org/10.1016/j.watres.2019.04.060.

Horton, Alice A., Alexander Walton, David J. Spurgeon, Elma Lahive, et Claus Svendsen. 2017. «Microplastics in Freshwater and Terrestrial Environments: Evaluating the Current Understanding to Identify the Knowledge Gaps and Future Research Priorities ». Science of The Total Environment 586 (mai): 127-41. https://doi.org/10.1016/j.scitotenv.2017.01.190.

Hotze, Ernest M., Tanapon Phenrat, et Gregory V. Lowry. 2010. « Nanoparticle Aggregation: Challenges to Understanding Transport and Reactivity in the Environment ». Journal of Environment Quality 39 (6): 1909. https://doi.org/10.2134/jeq2009.0462.

Hu, Enzhu, Siyao Shang, Zhongtian Fu, Xin Zhao, Xiangli Nan, Yichun Du, et Xijuan Chen. 2020. «Cotransport of Naphthalene with Polystyrene Nanoplastics (PSNP) in Saturated Porous Media: Effects of PSNP/Naphthalene Ratio and Ionic Strength ». Chemosphere 245 (avril): 125602. https://doi.org/10.1016/j.chemosphere.2019.125602.

Hurley, Rachel R., et Luca Nizzetto. 2018. «Fate and Occurrence of Micro(Nano)Plastics in Soils: Knowledge Gaps and Possible Risks ». Current Opinion in Environmental Science \& Health 1 (février): 6-11. https://doi.org/10.1016/j.coesh.2017.10.006.

Liu, Mengting, Shibo Lu, Yang Song, Lili Lei, Jiani Hu, Weiwei Lv, Wenzong Zhou, et al. 2018. « Microplastic and Mesoplastic Pollution in Farmland Soils in Suburbs of Shanghai, China ». Environmental Pollution 242 (novembre): 855-62. https://doi.org/10.1016/j.envpol.2018.07.051. 
Napper, Imogen E., et Richard C. Thompson. 2019. « Environmental Deterioration of Biodegradable, Oxo-Biodegradable, Compostable, and Conventional Plastic Carrier Bags in the Sea, Soil, and Open-Air Over a 3-Year Period ». Environmental Science \& Technology 53 (9): 4775-83. https://doi.org/10.1021/acs.est.8b06984.

Ng, E.-L., E. Huerta Lwanga, S.M. Eldridge, P. Johnston, H.-W. Hu, V. Geissen, et D. Chen. 2018. «An overview of microplastic and nanoplastic pollution in agroecosystems ». Science of the Total Environment 627: 1377-88. https://doi.org/10.1016/j.scitotenv.2018.01.341.

Pinto da Costa, João, Ana Paço, Patrícia S. M. Santos, Armando C. Duarte, et Teresa Rocha-Santos. 2019. « Microplastics in Soils: Assessment, Analytics and Risks ». Environmental Chemistry 16 (1): 18. https://doi.org/10.1071/EN18150.

PlasticsEurope. 2019. « Plastics—The Facts 2019: An analysis of European plastics production, demand and waste data ».

Pradel, Alice, Hind el Hadri, Cloé Desmet, Jessica Ponti, Stéphanie Reynaud, Bruno Grassl, et Julien Gigault. 2020. «Deposition of Environmentally Relevant Nanoplastic Models in Sand during Transport Experiments ». Chemosphere 255 (septembre): 126912. https://doi.org/10.1016/j.chemosphere.2020.126912.

Programme, United Nations Environment. 2016. Marine Plastic Debris and Microplastics: Global Lessons and Research to Inspire Action and Guide Policy Change. https://doi.org/DEP/2010/nA.

Rillig, Matthias C. 2012. « Microplastic in Terrestrial Ecosystems and the Soil? » Environmental Science \& Technology 46 (12): 6453-54. https://doi.org/10.1021/es302011r.

Scalenghe, Riccardo. 2018. « Resource or Waste? A Perspective of Plastics Degradation in Soil with a Focus on End-of-Life Options ». Heliyon 4 (12): e00941. https://doi.org/10.1016/j.heliyon.2018.e00941.

Shen, Maocai, Yaxin Zhang, Yuan Zhu, Biao Song, Guangming Zeng, Duofei Hu, Xiaofeng Wen, et Xiaoya Ren. 2019. «Recent Advances in Toxicological Research of Nanoplastics in the Environment: A Review ». Environmental Pollution 252 (septembre): 511-21. https://doi.org/10.1016/j.envpol.2019.05.102. 
Steinmetz, Zacharias, Claudia Wollmann, Miriam Schaefer, Christian Buchmann, Jan David, Josephine Tröger, Katherine Muñoz, Oliver Frör, et Gabriele Ellen Schaumann. 2016. «Plastic Mulching in Agriculture. Trading Short-Term Agronomic Benefits for Long-Term Soil Degradation? » Science of The Total Environment 550 (avril): 690-705. https://doi.org/10.1016/j.scitotenv.2016.01.153.

Ter Halle, Alexandra, Laurent Jeanneau, Marion Martignac, Emilie Jardé, Boris Pedrono, Laurent Brach, et Julien Gigault. 2017. « Nanoplastic in the North Atlantic Subtropical Gyre ». Environmental Science \& Technology 51 (23): 13689-97. https://doi.org/10.1021/acs.est.7b03667.

Tsuge, Shin, Hajima Ohtani, et Chuichi Watanabe. 2011. Pyrolysis-GC/MS Data Book of Synthetic Polymers: Pyrograms, Thermograms and MS of Pyrolyzates. 1st ed. Amsterdam ; Boston: Elsevier.

Velzeboer, I., C. J. A. F. Kwadijk, et A. A. Koelmans. 2014. « Strong Sorption of PCBs to Nanoplastics, Microplastics, Carbon Nanotubes, and Fullerenes ». Environmental Science \& Technology 48 (9): 4869-76. https://doi.org/10.1021/es405721v.

Watteau, Francoise, Marie-France Dignac, Adeline Bouchard, Agathe Revallier, et Sabine Houot. 2018. « Microplastic Detection in Soil Amended With Municipal Solid Waste Composts as Revealed by Transmission Electronic Microscopy and Pyrolysis/GC/MS ». Frontiers in Sustainable Food Systems 2. https://doi.org/10.3389/fsufs.2018.00081.

Zhu, Bo-Kai, Yi-Meng Fang, Dong Zhu, Peter Christie, Xin Ke, et Yong-Guan Zhu. 2018. « Exposure to Nanoplastics Disturbs the Gut Microbiome in the Soil Oligochaete Enchytraeus Crypticus ». Environmental Pollution 239 (août): 408-15. https://doi.org/10.1016/j.envpol.2018.04.017. 